\title{
Clinical utility gene card for: Tuberous sclerosis complex (TSC1, TSC2)
}

\author{
Karin Mayer ${ }^{\star, 1}$, Christa Fonatsch ${ }^{2}$, Katharina Wimmer ${ }^{3}$, Ans MW van den Ouweland ${ }^{4}$ and \\ Anneke JA Maat-Kievit ${ }^{4}$
}

European Journal of Human Genetics (2014) 22, doi:10.1038/ejhg.2013.129; published online 12 June 2013

\section{DISEASE CHARACTERISTICS}

\subsection{Name of the disease (synonyms)}

Tuberous sclerosis complex (TSC), Bourneville-Pringle disease.

\subsection{OMIM\# of the disease \\ 191100,613254 .}

1.3 Name of the analysed genes or DNA/chromosome segments TSC1, TSC2.

\subsection{OMIM\# of the gene(s)}

605284, 191092.

\subsection{Mutational spectrum}

Missense, nonsense, and splice site mutations; insertions, deletions, genomic rearrangements, microdeletions, intragenic differences of gene dose/changes of copy number (duplications or deletions of one or more exons).

Presently, more than 450 different disease-causing mutations are known for TSC1 and more than 1300 for TSC2, respectively. The vast majority (80\%) of TSC1 mutations are truncating comprising frameshift, nonsense, and splice mutations. Missense changes represent $17 \%$ and large genomic deletions are rare (3\%). Truncating mutations $(65 \%)$ are also the most common mutation type in the TSC2 gene. In contrast to the TSC1 gene, missense mutations (26\%) and large genomic deletions $(6 \%)$ occur substantially more frequently. Mutations that have been published in the literature and mutations submitted without publication are available in the Tuberous sclerosis database. ${ }^{1}$

\subsection{Analytical methods}

For detection of point mutations and small insertions/deletions: complete analysis of all coding regions and neighbouring intron sequences (splice sites) in genomic DNA, by sequence analysis or other techniques with a sensitivity comparable to sequence analysis.

For detection of intragenic deletions and duplications with differences of gene dose: analysis of both genes, for example, by MLPA (multiplex ligation dependent probe amplification) or quantitative PCR.
For detection of chromosomal rearrangements, oligo and SNP array analyses can be performed. An exception is a microdeletion, particularly a TSC2/PKD1 contiguous gene syndrome, which can be detected by FISH (fluorescence in situ hybridisation). ${ }^{2}$

Next-generation sequencing approaches can also be used.

\subsection{Analytical validation}

Bidirectional sequence analysis or other methods with a comparable sensitivity as sequence analysis; confirmation of results by a second DNA extraction or a second method; confirmation of intragenic or larger chromosomal deletions by a second method, for example, quantitative PCR, long-range PCR, and FISH. Variants of unknown significance should be further investigated at least by in silico analysis and, if possible, by segregation analysis. In some cases (especially for some missense and splice site variants), it can be still unclear whether these variants are disease-causing or rare neutral variants. Functional tests can be used to help resolve whether these variants are likely to be disease-causing. ${ }^{3}$ Intronic variants, missense, and synonymous changes that are suspected to affect RNA splicing should be verified by investigating an RNA sample, applying RT-PCR for example.

1.8 Estimated frequency of the disease (incidence at birth ('birth prevalence') or population prevalence)

Birth incidence is estimated to be $1: 6000 .{ }^{4}$ Numbers for prevalence range from 0.7 to 3.8 per 100000 population in the United Kingdom 5 assuming no differences in other ethnical groups.

1.9 If applicable, prevalence in the ethnic group of investigated person

Not applicable.

\subsection{Diagnostic setting}

\begin{tabular}{lll}
\hline & Yes & No. \\
A. (Differential) diagnostics & $\bigotimes$ & $\square$ \\
B. Predictive Testing & $\Downarrow$ & $\square$ \\
C. Risk assessment in relatives & $\Downarrow$ & $\square$ \\
D. Prenatal & $\Downarrow$ & $\square$ \\
\hline
\end{tabular}
University Innsbruck, Innsbruck, Austria; ${ }^{4}$ Department Clinical Genetics, Erasmus Medical Center, Rotterdam, The Netherlands

${ }^{*}$ Correspondence: Dr K Mayer, Center for Human Genetics and Laboratory Diagnostics, Department of Molecular Genetics, Dr. Klein, Dr. Rost and Colleagues, Lochhamer Street 29, D-82152 Martinsried, Germany. Tel: +49 89895578 0; Fax: +49 89895578 780; E-mail: Karin.Mayer@medizinische-genetik.de 
Comment:

Prenatal genetic testing including polar body analysis and preimplantation genetic testing is available for families with a known genetic cause of TSC. Caveat: (germline) mosaicism ${ }^{6}$ in one of the parents of a patient if they both test negative for the constitutive mutation, offer prenatal testing for new pregnancies, and offer to test other siblings of the patient.

\section{TEST CHARACTERISTICS}

\begin{tabular}{|c|c|c|c|c|}
\hline & \multicolumn{2}{|c|}{ Genotype or disease } & \multirow{2}{*}{$\begin{array}{l}\text { A: True positives } \\
\text { B: False positives }\end{array}$} & \multirow{2}{*}{$\begin{array}{l}\text { C: False negative } \\
\text { D: True negative }\end{array}$} \\
\hline & Present & Absent & & \\
\hline \multicolumn{5}{|l|}{ Test } \\
\hline \multirow[t]{2}{*}{ Positive } & A & B & Sensitivity: & $A /(A+C)$ \\
\hline & & & Specificity: & $D /(D+B)$ \\
\hline \multirow[t]{2}{*}{ Negative } & C & D & Positive predictive value: & $A /(A+B)$ \\
\hline & & & Negative predictive value: & $D /(C+D)$ \\
\hline
\end{tabular}

\subsection{Analytical sensitivity}

(proportion of positive tests if the genotype is present)

Assuming a prevalence of $90 \%$ for point mutations and of up to $10 \%$ for intragenic deletions/duplications, microdeletions and rearrangements, germline mutations will be detected in $80-85 \%$ of cases ${ }^{7}$ if both genes are analysed by multiple methods, including a deletion/ duplication screen. Rare splice mutations located deep in introns or mutations affecting mRNA expression (for example in promoter regions) are not detected by current DNA-based diagnostics but can be identified with RNA-based methods. ${ }^{8}$ Additional mutations not detected by routine diagnostic methods like Sanger sequencing and MLPA may be identified applying next-generation sequencing approaches. ${ }^{9,10}$

\subsection{Analytical specificity \\ (proportion of negative tests if the genotype is not present) \\ Nearly $100 \%$.}

\subsection{Clinical sensitivity}

(proportion of positive tests if the disease is present)

The clinical sensitivity can be dependent on variable factors such as age or family history or incomplete clinical investigations performed. In such cases, a general statement should be given, even if a quantification can only be made case by case.

Clinical sensitivity reaches $70-85 \%$ if the diagnostic criteria of Roach ${ }^{11}$ are fulfilled (corresponding to 'TSC definite'), depending on the application of one or more analytical methods. ${ }^{12-15}$ Because of variable clinical expressivity, lower sensitivities are expected in phenotypes corresponding to 'TSC probable' and 'TSC possible'.

\subsection{Clinical specificity}

(proportion of negative tests if the disease is not present)

The clinical specificity can be dependent on variable factors such as age or family history or number of clinical investigations performed. In such cases, a general statement should be given, even if a quantification can only be made case by case.

Clinical specificity is possibly $100 \%$.

2.5 Positive clinical predictive value

(life-time risk to developing the disease if the test is positive)
As there is an almost $100 \%$ penetrance, clinical predictive value is $100 \%$. However, there may be highly variable clinical expressivity. ${ }^{16}$

\subsection{Negative clinical predictive value} (probability of not developing the disease if the test is negative)

Assume an increased risk based on family history for a non-affected person. Allelic and locus heterogeneity may need to be considered.

Index case in that family had been tested:

If the pathogenic mutation is identified in the index patient and is tested negative in another family member, then the clinical predictive value for the family member is almost $100 \%$.

Index case in that family had not been tested:

$85 \%$. This question arises in children who have no clinical symptoms yet, or in adults with minimal clinical symptoms such that the diagnosis cannot be made by clinical criteria alone.

\section{CLINICAL UTILITY}

\section{1 (Differential) diagnostics: The tested person is} clinically affected

(To be answered if in 1.10 'A' was marked)

\subsubsection{Can a diagnosis be made other than through a genetic test?}

\begin{tabular}{|c|c|}
\hline$凶$ & \\
\hline Clinically & $\otimes$ \\
\hline Imaging & $凶$ \\
\hline Endoscopy & $\square$ \\
\hline Biochemistry & $\square$ \\
\hline Electrophysiology & $\square$ \\
\hline Other (please describe) & $\begin{array}{l}\text { Through clinical and imaging investigations, a } \\
\text { definite diagnosis of TSC can be made if the } \\
\text { diagnostic criteria are fulfilled. The diagnosis can } \\
\text { be 'probable' or 'possible', owing to the variable } \\
\text { expressivity of the clinical signs, young age, or } \\
\text { mosaicism. In the latter, a diagnosis may be arrived } \\
\text { at if DNA for TSC testing of the tissue in question, } \\
\text { in case of segmental or somatic mosaicism, is } \\
\text { available through surgery or biopsy. Also with weak } \\
\text { clinical manifestations (eg, only angiomyolipoma } \\
\text { (AML) of the kidney or cortical tubers in the brain) } \\
\text { the diagnosis of TSC requires the detection of a } \\
\text { causative mutation. }{ }^{17} \text { If the diagnostic criteria for } \\
\text { TSC are not definite in a parent or another first } \\
\text { degree relative of an affected person with an } \\
\text { identified TSC mutation, mutation analysis can } \\
\text { confirm the diagnosis and may guide genetic } \\
\text { counselling. }\end{array}$ \\
\hline
\end{tabular}

\subsubsection{Describe the burden of alternative diagnostic methods to the} patient

There is no extra burden of the alternative diagnostic methods to a patient. When TSC is suspected in a patient, full clinical and imaging investigations are needed, to get insight into the clinical status of the patient and to guide further follow-up. Because of the variability of TSC, investigation of different organ systems are needed, like a neurological examination, MRI of the brain, cardiological examination, ultrasound of the heart, ophthalmological examination, dermatological examination, and ultrasound or CT-scan of the abdomen. $^{18,19}$ 
There is an extra burden for relatives who want to know their risk in the absence of a TSC1 or TSC2 mutation in the patient. The parents or other first degree relatives of a patient have to undergo the aforementioned investigation protocol to exclude as far as possible or confirm the diagnosis. In only about $1 / 3$ of the cases, do the clinical investigations of the parents define the clinical status and follow-up of the affected parent. Also no prenatal or preimplantation genetic testing can be offered in the absence of a mutation. Although blood is required for a DNA test, it is less uncomfortable and less time consuming for relatives, to be tested in this way. Caveat: (germline) mosaicism.

During initial diagnosis as well as after molecular confirmation of the clinical diagnosis, clinical and imaging investigations are required at regular intervals. The length of the intervals depends on the clinical findings.

\subsubsection{How is the cost effectiveness of alternative diagnostic methods to be judged?}

The authors presume that it is cheaper to exclude at-risk relatives using a DNA test than by using the full clinical investigation protocol.

3.1.4 Will disease management be influenced by the result of a genetic test?

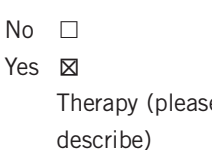

Prognosis (please describe)

Management (please describe)

3.2 Predictive Setting: The tested person is clinically unaffected but carries an increased risk based on family history

(To be answered if in 1.10 ' $\mathrm{B}$ ' was marked)

\subsubsection{Will the result of a genetic test influence lifestyle and prevention?}

If the test result is positive (please describe):

Specific follow-up investigations of the organ systems that are potentially involved in TSC are needed in regular intervals. The length of the intervals depends on the clinical findings and protocol. Early diagnosis may allow early initiation of treatment and/or surveillance.
Treatment options can affect lifestyle. Prenatal or preimplantation genetic testing can be offered because of a $50 \%$ risk for the fetus/ embryo.

If the test result is negative (please describe):

There is no need of control investigations if a familial mutation has been excluded. In case of TSC-associated complaints or symptoms, clinical examination is considered useful. Prenatal testing can be offered because there is a risk of a germline mosaic of $1-2 \%$ for the fetus.

3.2.2 Which options in view of lifestyle and prevention does a person at-risk have if no genetic test has been done (please describe)? Regular interdisciplinary follow-up of the organ systems potentially involved in TSC.

3.3 Genetic risk assessment in family members of a diseased person (To be answered if in 1.10 ' $\mathrm{C}$ ' was marked)

\subsubsection{Does the result of a genetic test resolve the genetic situation in} that family?

Yes, in most cases, although mosaicism in the parents cannot be excluded.

3.3.2 Can a genetic test in the index patient save genetic or other tests in family members?

No.

3.3.3 Does a positive genetic test result in the index patient enable a predictive test in a family member?

Yes.

\subsection{Prenatal diagnosis}

(To be answered if in 1.10 'D' was marked)

\subsubsection{Does a positive genetic test result in the index patient enable a} prenatal diagnosis?

Yes, if either a parent carries the mutation or if a sibling carries the mutation in case of germline mosaicism of one parent.

\section{IF APPLICABLE, FURTHER CONSEQUENCES OF TESTING}

Please assume that the result of a genetic test has no immediate medical consequences. Is there any evidence that a genetic test is nevertheless useful for the patient or his/her relatives? (Please describe)

Yes. The genetic diagnosis significantly contributes to classification of the disease if the diagnostic criteria alone are not sufficient for securing the clinical diagnosis. Due to an update in the diagnostic criteria, the identification of either a TSC1 or TSC2 pathogenic mutation in DNA from normal tissue is sufficient to make a definite diagnosis of TSC. ${ }^{25}$ A definite diagnosis is a prerequisite for clinical prognosis, specific therapy, and legal acceptance as a severely disabled person. For many patients, the definite genetic diagnosis of TSC provides certainty, ends a diagnostic odyssey, and enables accurate genetic counselling of patients and relatives. Finally, the correct diagnosis of TSC enables finding the appropriate patient organisation.

\section{CONFLICT OF INTEREST}

The authors declare no conflict of interest.

\section{ACKNOWLEDGEMENTS}

This work was supported by EuroGentest2 (Unit 2: 'Genetic testing as part of health care'), a Coordination Action under FP7 (Grant Agreement Number 261469), and the European Society of Human Genetics. 
1 Tuberous sclerosis database: http://chromium.liacs.nl/LOVD2/TSC/home.php?select_db=TSC1, http://chromium.liacs.nl/LOVD2/TSC/home.php?select_db=TSC2

2 Brook-Carter PT, Peral B, Ward CJ et al: Deletion of the TSC2 and PKD1 genes associated with severe infantile polycystic kidney disease-a contiguous gene syndrome. Nat Genet 1994; 8: 328.

3 Hoogeveen-Westerveld M, Wentink M, van den Heuvel D et al: Functional assessment of variants in the TSC1 and TSC2 genes identified in individuals with tuberous sclerosis complex. Hum Mutat 2011; 32: 424-435.

4 Osborne JP, Fryer A, Webb D: Epidemiology of tuberous sclerosis. Ann N Y Acad Sci 1991; 615: 125-127.

5 O'Callaghan FJ, Shiell AW, Osborne JP, Martyn CN: Prevalence of tuberous sclerosis estimated by capture-recapture analysis. Lancet 1998; 351: 1490.

6 Roberts PS, Dabora S, Thiele EA, Franz DN, Jozwiak S, Kwiatkowski DJ: Somatic mosaicism is rare in unaffected parents of patients with sporadic tuberous sclerosis. J Med Genet 2004; 41: e69.

7 Kwiatkowski DJ: Tuberous sclerosis complex. genes, clinical features and therapeutics, in: Kwiatkowski, Holets Whittemore, Thiele (eds.), 2010; chap. II.4, pp 29-57.

8 Mayer K, Ballhausen W, Rott HD: Mutation screening of the entire coding regions of the TSC1 and the TSC2 gene with the protein truncation test (PTT) identifies frequent splicing defects. Hum Mutat 1999; 14: 401-411.

9 Qin W, Kozlowski P, Taillon BE et al: Ultra deep sequencing detects a low rate of mosaic mutations in tuberous sclerosis complex. Hum Genet 2010; 127: 573-582.

10 Mayer K, Wagner C, Scholz M, Datter S, Vogl I, Rost I: Different next generation sequencing approaches detect mosaic mutations and deep intronic mutations in tuberous sclerosis complex; Abstract P11.132 Eur J Hum Genet 2012; 20 (Supp1): 287.

11 Roach ES, Gomez MR, Northrup H: Tuberous sclerosis complex consensus conference: revised clinical diagnostic criteria. J Child Neurol 1998; 13: 624-628.

12 Jones AC, Shyamsundar MM, Thomas MW et al: Comprehensive mutation analysis of TSC1 and TSC2-and phenotypic correlations in 150 families with tuberous sclerosis. Am J Hum Genet 1999; 64: 1305-1315.

13 Dabora SL, Jozwiak S, Franz DN et al: Mutational analysis in a cohort of 224 tuberous sclerosis patients indicates increased severity of TSC2, compared with TSC1, disease in multiple organs. Am J Hum Genet 2001; 68: 64-80.

14 Sancak O, Nellist M, Goedbloed M et al: Mutational analysis of the TSC1 and TSC2 genes in a diagnostic setting: genotype-phenotype correlations and comparison of diagnostic DNA techniques in tuberous sclerosis complex. Eur J Hum Genet 2005; 13: $731-741$.

$15 \mathrm{Au}$ KS, Williams AT, Roach ES et al: Genotype/phenotype correlation in 325 individuals referred for a diagnosis of tuberous sclerosis complex in the United States. Genet Med 2007; 9: 88-100.

16 Lyczkowski DA, Conant KD, Pulsifer MB et al: Intrafamilial phenotypic variability in tuberous sclerosis complex. J Child Neurol 2007; 22: 1348-1355.

17 Crino PB, Aronica E, Baltuch G, Nathanson KL: Biallelic TSC gene inactivation in tuberous sclerosis complex. Neurology 2010; 74: 1716-1723.

18 Curatolo P, Jóźwiak S, Nabbout R: TSC consensus meeting for SEGA and epilepsy management. Management of epilepsy associated with tuberous sclerosis complex (TSC): clinical recommendations. Eur J Paediatr Neurol 2012 16: $582-586$.

19 Yates JR, Maclean C, Higgins JN et al: Tuberous Sclerosis 2000 Study Group. The Tuberous Sclerosis 2000 Study: presentation, initial assessments and implications for diagnosis and management. Arch Dis Child 2011; 96: 1020-1025.

20 Franz DN, Belousova E, Sparagana S et al: Efficacy and safety of everolimus for subependymal giant cell astrocytomas associated with tuberous sclerosis complex (EXIST-1): a multicentre, randomised, placebo-controlled phase 3 trial. Lancet 2013; 381: 125-132.

21 Bissler JJ, Kingswood JC, Radzikowska E et al: Everolimus for angiomyolipoma associated with tuberous sclerosis complex or sporadic lymphangioleiomyomatosis (EXIST-2): a multicentre, randomised, double-blind, placebo-controlled trial. Lancet 2013; S0140-S6736: 61767-66176.

22 Yu J, Henske EP: mTOR activation, lymphangiogenesis, and estrogen-mediated cell survival: the "perfect storm" of pro-metastatic factors in LAM pathogenesis. Lymphat Res Biol 2010; 8: 43-49.

23 van Eeghen AM, Black ME, Pulsifer MB, Kwiatkowski DJ, Thiele EA: Genotype and cognitive phenotype of patients with tuberous sclerosis complex. Eur J Hum Genet 2012; 20: 510-515.

24 van Eeghen AM, Nellist M, van Eeghen EE, Thiele EA: Central TSC2 missense mutations are associated with a reduced risk of infantile spasms. Epilepsy Res 2012; 103: 83-87.

25 TSC Clinical Consensus Conference, Washington, DC, 14-15 June 2012 (personal communication). 